\title{
ACCOUNTING STUDENT LEADERSHIP BEHAVIOR: A DILEMMA FOR HIGHER EDUCATION
}

\author{
Yusep Mulyana' ${ }^{1}$ Asep Kurniawan ${ }^{2}$
}

${ }^{12}$ Sekolah Tinggi Ilmu Ekonomi Sutaatmadja, Subang, Indonesia yusepmulyana48@gmail.com

\begin{tabular}{|c|c|}
\hline INFO ARTIKEL & ABSTRAK/ABSTRACT \\
\hline $\begin{array}{l}\text { Histori Artikel : } \\
\text { Tgl. Masuk : } 02 \text { November } 2019 \\
\text { Tgl. Diterima : } 29 \text { November } 2019 \\
\text { Tersedia Online : } 23 \text { Desember } 2019 \\
\text { Keywords: } \\
\text { Behavior, Leadership Behavior, } \\
\text { Accounting }\end{array}$ & $\begin{array}{l}\text { The position and role of accountants in organizations is not } \\
\text { related to decision making positions and for this reason } \\
\text { accounting students do not identify themselves as leaders } \\
\text { in their future careers. Motivated by these assumptions, this } \\
\text { study aims to determine the relationship between curriculum } \\
\text { and ethics on career choices of accounting students and to } \\
\text { find out the relationship between curriculum and decision } \\
\text { making processes on accounting student leadership } \\
\text { behavior. The samples used in the study were } 70 \\
\text { respondents from STIESA accounting students and KUIS } \\
\text { accounting students. Analysis of the data in this study uses } \\
\text { correlation analysis with the help of SPSS version } 22 \text {. The } \\
\text { results of the analysis show that the relationship between } \\
\text { curriculum and career choices in STIESA is negative, in } \\
\text { QUIZ is positive and when combined STIESA and QUIZ the } \\
\text { relationship that occurs is positive. The relationship that } \\
\text { occurs between ethics and career choices in STIESA, QUIZ } \\
\text { and in general when the analysis is combined is positive. } \\
\text { While the relationship between curriculum and leadership } \\
\text { behavior at STIESA is negative, the QUI is positive and the } \\
\text { combination of STIESA and QUI is positive. Then the } \\
\text { relationship that occurs between the decision making } \\
\text { process and leadership behavior in STIESA, QUIZ and in } \\
\text { general when the analysis is combined between STIESA } \\
\text { students and QUI students is positive. }\end{array}$ \\
\hline
\end{tabular}

\section{PENDAHULUAN}

Saat ini, skandal keuangan telah membawa peran akuntan ke dalam organisasi dan kebutuhan akan profesi akuntan dengan kategori profesional tengah mendapatkan perhatian dari berbagai komunitas ilmiah dan bisnis. Untuk dapat mengejar visi dan misi organisasi, salah satu keterampilan yang harus dimiliki oleh seorang akuntan yakni dengan meningkatkan keterampilan kepemimpinan. Berawal dari situasi di mana tidak cukup berkembangnya keterampilan kepemimpinan dan juga keterampilan profesional lainnya dalam program akuntansi (Kavanagh \& Drennan 2008), peneliti mengevaluasi mengenai harapan mahasiswa akuntansi dengan mengukur struktur kurikulum, citra profesi akuntansi di masyarakat, partisipasi 
mahasiswa dalam proses pengambilan keputusan di tingkat fakultas, nilai-nilai etis mahasiswa, sumber-sumber perilaku kepemimpinan, dan perilaku kepemimpinan.

Kepemimpinan sebagai fenomena kualitatif diidentifikasi sebagai bagian dari budaya organisasi. Tempat para akuntan dalam posisi organisasional yang kontroversial ini sulit untuk dijelaskan, karena itu merupakan pertentangan antara citra pemimpin dan citra akuntan. Pertentangan ini digarisbawahi oleh kepahitan para akuntan untuk mengembangkan sistem birokrasi. Kepemimpinan dianggap sebagai praktik diskursif (Clifton, 2014) dan akuntabilitas dianggap sebagai proses administrasi (Fogarty \& Al-Kazemi, 2011). Profesi akuntansi memainkan peran yang penting dalam organisasi dan untuk memperkuat organisasi maka para pemimpin harus mempertimbangkan kembali posisi dari para akuntan. Mahasiswa akuntansi menganggap profesi masa depan mereka sebagai kepastian yang memberi mereka kestabilan.

Hal yang patut dipertanyakan mengenai perilaku kepemimpinan mahasiswa akuntansi STIESA yaitu minimnya mahasiswa akuntansi STIESA yang memiliki peran sebagai pemimpin dalam berbagai pelaksanaan kegiatan kemahasiswaan di kampus. Mayoritas posisi ketua atau pemimpin dalam suatu kegiatan diduduki oleh mahasiswa dari program studi manajemen. Sehingga hal tersebut menimbulkan pertanyaan mengenai kemampuan dari mahasiswa akuntansi STIESA ketika diberikan amanah sebagai seorang pemimpin. Padahal berbagai kegiatan di kampus tersebut merupakan sebagai sarana untuk melatih diri dan mengaplikasikan berbagai ilmu yang telah diperoleh selama kegiatan perkuliahan.

Sementara itu mahasiswa akuntansi di KUIS beranggapan bahwa masih rendahnya pengetahuan yang diberikan untuk meningkatkan keterampilanketerampilan profesional yang dicantumkan dalam struktur kurikulum. Salah satu keterampilan yang dianggap masih kurang yaitu mengenai perilaku kepemimpinan. Untuk menghadapi situasi tersebut, tentu dalam mengembangkan kurikulum harus melibatkan semua pihak. Sehingga kurikulum tersebut dapat diterapkan dengan baik dan sesuai dengan kondisi perekonomian dan bisnis sekarang. Salah satu pihak yang harus dilibatkan dalam mengembangkan kurikulum yaitu mahasiswa akuntansi itu sendiri. Karena yang merasakan hasil dari kurikulum yang diterapkan adalah mahasiswa yang bersangkutan. 
Peneliti mulai dengan mendefinisikan harapan mahasiswa akuntansi dalam hal kurikulum pendidikan; Kemudian, peneliti menawarkan gambaran karir masa depan mereka berdasarkan perbedaan antara persepsi mahasiswa dalam posisi kepemimpinan dan citra profesi akuntan di masyarakat. Selanjutnya kita akan membahas dan hasilnya mengarah pada kesimpulan mengenai faktor-faktor yang berkorelasi dengan pilihan karir dan perilaku kepemimpinan mahasiswa akuntansi di STIESA dan KUIS.

\section{KERANGKA TEORITIS DAN PENGEMBANGAN HIPOTESIS}

\section{Kurikulum akuntansi}

Menurut Permendikbud no. 49/2014 kurikulum adalah seperangkat rencana dan pengaturan mengenai capaian pembelajaran, bahan kajian, proses, dan penilaian yang digunakan sebagai pedoman penyelenggaraan program studi. Untuk menghadapi persaingan didalam dunia kerja, kurikulum akuntansi ke depan harus mempertimbangkan kurikulum dengan cakupan yang lebih luas yang berisi set keterampilan dan atribut yang melebihi kemampuan teknis murni (Kavanagh dan Drenman, 2008). Selain memberikan pemahaman secara teori, kurikulum akuntansi juga diharapkan membekali mahasiswanya dengan kreativitas, ilmu sosial kritis dan pembangunan mental. Sehingga diharapkan selain menghasilkan lulusan akuntansi yang mampu untuk menyusun laporan keuangan, tetapi memiliki kemampuan-kemampuan lainnya untuk bekal mereka dalam bersaing didalam dunia kerja.

\section{Pilihan karir (image akuntan)}

$\begin{array}{rrr}\text { Menurut } & \text { Saputra (2015) karir } \\ \text { adalah proses } & \text { seseorang dalam }\end{array}$
membangun pekerjaan atau meniti pekerjaan secara bertahap untuk mendapatkan hasil yang maksimal atau yang diharapkan seseorang tersebut dalam jangka waktu tertentu.

Menurut kamus besar bahasa indonesia yang dimaksud dengan karir yaitu suatu proses perkembangan dan kemajuan diri dalam dunia pekerjaan, jabatan, dan profesi atau pekerjaan yang memberikan harapan untuk maju dalam bidang profesi atau pekerjaan. Pemilihan karir merupakan suatu cara atau usaha seseorang mengambil satu di antara banyak jabatan atau pekerjaan yang memberikan harapan untuk maju dan sesuai dengan yang diinginkan.

\section{Menurut International Federation} Accountant karir yang termasuk dalam bidang akuntan yakni meliputi akuntan publik dan akuntan non publik. Akuntan publik adalah profesi yang memberikan jasa asurans (jasa audit, jasa review, jasa 
asurans lainya) bertujuan untuk memberikan keyakinan bagi para pengguna atas hasil evaluasi atau pengukuran informasi keuangan dan non keuangan berdasarkan suatu kriteria (UU No. 5 Th 2011 pasal 3 ayat 1). Sementara yang termasuk ke dalam akuntan non publik meliputi akuntan pendidik, akuntan manajemen, dan akuntan pemerintah.

\section{Etika akuntansi}

Menurut Carl S.Warren etika yaitu prinsip moral yang mengarahkan individu dalam bertindak. Tujuan akuntansi yaitu menyediakan informasi yang relevan dan tepat waktu untuk pengambilan keputusan bagi pemangku kepentingan. Akuntan harus bersikap sesuai etika agar informasi yang mereka sediakan menjadi terpercaya dan oleh karena itu bermanfaat dalam pengambilan keputusan. Pimpinan dengan nilai etika yang baik diharapkan akan mengangkat kembali harkat profesi akuntansi dan membantu orang-orang untuk mulai melupakan skandal-skandal yang melibatkan para akuntan seperti pada kasus Enron, Worldcom dan Parmalat (Afriyenti, 2014).

\section{Perilaku kepemimpinan seorang akuntan}

Kepemimpinan adalah sebuah kompetensi penting di dalam profesi akuntansi. AICPA (American Institute of Certified Public Accountant) dalam

rerangka kompetensi inti memasuki profesi akuntansi menekankan pentingnya kemampuan kepemimpinan, yang meliputi kemampuan memotivasi orang lain, chair teams, dan memfasilitasi pengembangan konsensus (AICPA, 1999). Maka dari itu agar mampu bersaing dalam dunia kerja, salah satu keterampilan yang harus dimiliki oleh seorang lulusan akuntansi yaitu dengan memiliki keterampilan dalam hal kepemimpinan. Karena keterampilan kepemimpinan dianggap sebagai salah satu prasyarat penting keberhasilan mahasiswa akuntansi ketika memasuki dunia kerja.

\section{Keterlibatan dalam pengambilan keputusan}

Pengambilan keputusan menurut George R. Terry adalah pemilihan alternatif prilaku (kelakuan) dari dua atau lebih alternative yang ada. Pada hakikatnya peran akuntan dalam organisasi tidak berhubungan langsung dengan posisi pengambilan keputusan, oleh karena itu kebanyakan seorang akuntan tidak mengasah keterampilan mereka dalam membuat sebuah keputusan. Seiring dengan perkembangan bisnis, keterampilan yang harus dimiliki oleh seorang akuntan harus lebih kompleks lagi agar mereka mampu untuk bersaing didalam dunia kerja. 
Hubungan kurikulum dengan pilihan karir

Menurut Soedijarto, kurikulum merupakan serangkaian pengalaman dan kegiatan belajar yang direncanakan untuk diatasi oleh siswa dalam rangka mencapai tujuan pembelajaran yang telah ditetapkan oleh suatu lembaga pendidikan yang berwenang. Agar mahasiswa akuntansi yang sudah lulus dan siap terjun dalam dunia kerja lebih mudah menyesuaikan kemampuan yang dimilikinya dengan tuntutan dalam pekerjaan, maka kurikulum akuntansi yang diterapkan harus sesuai dan relevan dengan tuntutan dunia kerja (Sari, 2013). Kurikulum akuntansi diharapkan mampu untuk memberikan pengetahuanpengetahuan yang beragam dan keterampilan-keterampilan profesional. Sehingga dengan bekal ilmu yang dimiliki oleh mahasiswa akuntansi dapat membantu mereka dalam memilih karirnya dimasa yang akan datang. Berdasarkan uraian tersebut maka dalam penelitian ini dapat dirumuskan hipotesis sebagai berikut:

H1 : Kurikulum akuntansi berhubungan dengan pilihan karir

\section{Hubungan etika dengan pilihan karir}

Menurut Carl S.Warren etika yaitu prinsip moral yang mengarahkan individu dalam bertindak. Penelitian yang dilakukan oleh Wildiana (2014) menunjukkan adanya hubungan antara etika dengan pilihan karir.
Mahasiswa yang memiliki etika yang sangat baik dan sesuai dengan standar akuntansi, diharapkan dapat membantu mahasiswa dalam pemilihan karirnya. Berdasarkan uraian tersebut maka dalam penelitian ini dapat dirumuskan hipotesis sebagai berikut:

H2 : Etika berhubungan dengan pilihan karir

\section{Hubungan kurikulum dengan perilaku kepemimpinan}

Pengembangan kurikulum merupakan fondasi yang signifikan dalam mengembangkan kepemimpinan (Suyantiningsih). Untuk menumbuhkan perilaku kepemimpinan, maka kurikulum yang diterapkan harus memberikan pengetahuan-pengetahuan yang berkaitan dengan perilaku kepemimpinan. Sehingga kurikulum akuntansi tidak hanya terfokus terhadap ilmu-ilmu yang menjadi dasar akuntansi saja, tapi memberikan pengetahuan yang beragam sebagai bekal dari mahasiswa untuk bersaing didalam dunia kerja. Berdasarkan uraian tersebut maka dalam penelitian ini dapat dirumuskan hipotesis sebagai berikut:

H3 : Kurikulum akuntansi berhubungan dengan perilaku kepemimpinan

\section{Hubungan pengambilan keputusan dengan perilaku kepemimpinan}

Menurut G.R. Terry pengambilan keputusan adalah pemilihan alternative 
perilaku tertentu atau dari dua atau lebih alternative yang ada. Pengambilan keputusan yang efektif diharapkan menjadi tolak ukur kepemimpinan yang efektif pula. Karena bagaimanapun salah satu cara untuk melihat perilaku kepemimpinan seseorang yaitu sebaik apa dalam membuat sebuah keputusan untuk menyelesaaikan sebuah permasalahan. Berdasarkan uraian tersebut maka dalam penelitian ini dapat dirumuskan hipotesis sebagai berikut:

H4 : Pengambilan keputusan berhubungan dengan perilaku kepemimpinan

Kurikulum dan pengambilan keputusan sebagai sumber-sumber pembentuk perilaku kepemimpinan

Kurikulum dan pengambilan keputusan bisa dikatakan sebagai sumber terbentuknya perilaku kepemimpinan mahasiswa. Kurikulum memberikan ilmu dan pengetahuan secara teori, sementara pengambilan keputusan sebagai praktik nyata untuk menumbuhkan perilaku kepemimpinan. Semakin banyak pengetahuan mengenai perilaku kepemimpinan yang dicantumkan dalam kurikulum dan semakin sering seorang mahasiswa terlibat dalam proses pengambilan keputusan maka perilaku kepemimpinan mahasiswa akan semakin terbentuk dengan baik.

\section{METODOLOGI PENELITIAN}

Sampel penelitian terdiri dari 70 mahasiswa program studi Akuntansi yang berasal dari STIE Sutaatmadja (STIESA) dan Kolej Universiti Islam Antarbangsa Selangor (KUIS). Dengan rincian jumlah responden yang terdaftar sebagai mahasiswa STIESA sebanyak 36 responden dan yang berasal dari mahasiswa KUIS sebanyak 34 responden. Mahasiswa yang terdaftar di STIESA dan KUIS diperkenankan untuk mengisi kuesioner yang peneliti ajukan. Rincian sampel dari 70 mahasiswa akuntansi, $82,86 \%$ responden (58 individu) adalah perempuan dan $17,14 \%$ di antaranya (12 individu) adalah laki-laki. Usia responden berusia antara 19 dan 25 tahun dengan rata-rata berusia 20,93 tahun.

\section{Operasionalisasi Variabel}

Struktur kurikulum diukur dengan empat item: 'Saya puas dengan kedisiplinan dalam struktur kurikulum yang dapat mengembangkan perilaku kepemimpinan.'; 'Disiplin kepemimpinan yang tercantum dalam kurikulum fakultas memberikan ilmu bagi saya untuk mengembangkan perilaku kepemimpinan.'; 'Saya puas dengan informasi yang diberikan oleh para dosen dan kualitas interaksi antara saya dan para dosen.'; dan 'Saya puas dengan jumlah disiplin kepemimpinan yang diberikan 
oleh kurikulum fakultas.' Keempat item pernyataan tersebut memiliki koefisien reliabilitas sebesar 0,83 .

Citra profesi Akuntansi di masyarakat diukur dengan tiga item: 'Citra profesi akuntansi di mata masyarakat bukanlah sesuatu yang nyata.'; 'Profesi akuntansi menantang.'; dan 'Akuntan adalah karyawan yang berpengaruh dalam organisasi.' Ketiga item pernyataan tersebut memiliki koefisien reliabilitas sebesar 0,71 .

Partisipasi mahasiswa dalam proses pengambilan keputusan di tingkat fakultas diukur dengan empat item: 'Semua dosen mendorong adanya kolaborasi dan kerjasama dengan mahasiswa.'; 'Kurikulum fakultas mengembangkan visi mahasiswa.'; 'Semua dosen mendorong mahasiswa untuk mengatur sendiri nilainilai perilaku mahasiswa.'; dan 'Mahasiswa perlu dilibatkan dalam pengembangan kurikulum.' Keempat item pernyataan tersebut memiliki koefisien reliabilitas sebesar 0,80 .

Nilai etika mahasiswa diukur dengan tiga item: 'Nilai etika mahasiswa sesuai dengan standar akuntansi.'; 'Kurikulum mengembangkan nilai etika mahasiswa.'; dan 'Dosen selalu mendorong dan mempromosikan nilainilai etika.' Ketiga item tersebut memiliki koefisien reliabilitas sebesar 0,82 .
Sumber pengembangan perilaku kepemimpinan mahasiswa diukur dengan empat item: 'Saya menganggap bahwa sumber kepemimpinan adalah pengetahuan.'; 'Kurikulum adalah sumber untuk mengembangkan perilaku kepemimpinan saya.'; 'Saya pikir moralitas adalah sumber kepemimpinan.'; dan 'Budaya organisasi adalah sumber kepemimpinan.' Keempat item pernyataan tersebut memiliki koefisien reliabilitas sebesar 0,86 .

Keterampilan kepemimpinan mahasiswa diukur dengan empat item: 'Pengetahuan akuntansi saya lebih dari cukup untuk menjadi seorang pemimpin.'; 'Moralitas adalah kunci utama bagi saya sebagai pemimpin.'; 'Jika perilaku saya sesuai dengan standar akuntansi, saya akan menjadi pemimpin yang sangat baik.'; dan 'Saya tidak bisa membayangkan diri saya sebagai pengikut.' Keempat item pernyataan tersebut memiliki koefisien reliabilitas sebesar 0,72. Semua penilaian dilakukan dengan menggunakan skala Likert fivepoint ( 1 = sangat tidak setuju, 2 = tidak setuju, 3 = ragu-ragu, $4=$ setuju, dan 5 = sangat setuju). Alpha Cronbach dihitung untuk masing-masing konstruk dan hasilnya di atas 0,70. Hal ini menunjukkan reliabilitas dan validitas penelitian yang kuat, melebihi nilai 
ambang batas 0,70 yang direkomendasikan oleh Nunnally (1994).

\section{HASIL DAN PEMBAHASAN}

Peneliti mengajukan 22 item pernyataan untuk di isi oleh para responden dan kemudian dilakukan analisis lebih lanjut mengenai hasil dari jawaban para responden. Peneliti menggunakan SPSS 22 dalam melakukan pengolahan data. Tabel 1 menyajikan hasil pengolahan data untuk uji statistik deskriptif dan korelasi.

\section{Tabel 1}

Descriptive Statistics and Correlations Mahasiswa STIESA

\begin{tabular}{|c|c|c|c|c|c|c|c|c|}
\hline Variabel & $\begin{array}{c}\text { Mea } \\
\text { n }\end{array}$ & SD & 1 & 2 & 3 & 4 & 5 & 6 \\
\hline \begin{tabular}{|l} 
Struktur \\
Kurikulum
\end{tabular} & 3.79 & $\begin{array}{c}.37 \\
6\end{array}$ & $\begin{array}{c}1.00 \\
0\end{array}$ & \begin{tabular}{|c|}
- \\
.201 \\
\end{tabular} & .441 . & .451 & .040 & $\begin{array}{c}- \\
.118\end{array}$ \\
\hline $\begin{array}{l}\text { Citra Profesi } \\
\text { Akuntansi } \\
\end{array}$ & 3.85 & $\begin{array}{c}.42 \\
5 \\
\end{array}$ & \begin{tabular}{|c|}
- \\
201 \\
\end{tabular} & $\begin{array}{c}1.00 \\
0\end{array}$ & .364 . & .473 & .701 & 1.566 \\
\hline \begin{tabular}{|l|} 
Pengambila \\
n Keputusan
\end{tabular} & 3.87 & $\begin{array}{c}.39 \\
9\end{array}$ & .441 & .364 & $\begin{array}{c}1.00 \\
0\end{array}$. & .676 & .418 & .404 \\
\hline \begin{tabular}{|l|} 
Nilai-nilai \\
etika
\end{tabular} & 3.82 & \begin{tabular}{|c|}
48 \\
2
\end{tabular} & .451 & .473 & .676 & $\begin{array}{c}1.00 \\
0\end{array}$ & .423 . & 3.398 \\
\hline \begin{tabular}{|l|} 
Sumber \\
Kepemimpi \\
nan
\end{tabular} & 3.99 & $\mid \begin{array}{c}.38 \\
0\end{array}$ & .040 & .701 & .418 . & .423 & $\begin{array}{c}1.00 \\
0\end{array}$. & .399 \\
\hline $\begin{array}{l}\text { Keterampila } \\
\text { n } \\
\text { Kepemimpi } \\
\text { nan }\end{array}$ & 3.67 & $\begin{array}{c}44 \\
3\end{array}$ & $\begin{array}{c}- \\
.118\end{array}$ & .566 & .404 . & .398 & .399 & $\left(\begin{array}{c}1.00 \\
0\end{array}\right.$ \\
\hline
\end{tabular}

Sumber: Data SPSS diolah 2018

Hasil penelitian membuktikan bahwa hubungan antara struktur kurikulum dengan pilihan karir mahasiswa akuntansi STIESA bersifat negatif (-.201). Berdasarkan lampiran tabel 2 mahasiswa akuntansi STIESA merasa tidak setuju dengan asumsi bahwa citra profesi akuntansi di mata masyarakat bukanlah hal yang nyata $(\mathrm{M}=2,92, \mathrm{SD}=.770)$. Mahasiswa akuntansi STIESA menganggap bahwa profesi akuntansi itu sangat menantang $(\mathrm{M}=4,22, \mathrm{SD}=.485)$. Gambaran profesi akuntansi dapat ditingkatkan dengan keterlibatan aktif akuntan dalam kegiatan kepemimpinan, dan sebagai hasilnya akuntan harus menjadi karyawan berpengaruh dalam organisasi $(\mathrm{M}=4,42, \mathrm{SD}=.500)$.

Sementara itu hubungan antara etika dengan pilihan karir menunjukan adanya hubungan yang positif namun dengan korelasi yang lemah. Nilai korelasi antara etika dengan pilihan karir hanya sebesar (.473). Berdasarkan lampiran tabel 4 masih terdapat keraguan mengenai etika dari mahasiswa akuntansi di STIESA dalam menentukan nilai etika mahasiswa dengan standar akuntansi $(\mathrm{M}=3,58, \mathrm{SD}=$ $.692)$.

Kemudian untuk menjawab pertanyaan penelitian kedua, hasil tabel diatas menunjukan korelasi yang terjadi antara kurikulum dan perilaku kepemimpinan yaitu korelasi yang bersifat negatif (-.118). Hal itu terjadi karena mahasiswa akuntansi STIESA tidak merasa yakin dengan pengetahuan yang dimilikinya yang dapat dijadikan modal sebagai seorang pemimpin $(\mathrm{M}=3,28, \mathrm{SD}$ $=$.741) (Lampiran tabel 6), dan masih ada keraguan dalam menentukan diri mereka 
baik sebagai pemimpin maupun sebagai pengikut $(\mathrm{M}=3,42 \mathrm{SD}=.732)$.

Sementara itu hasil pengolahan dari tabel diatas menunjukan adanya korelasi antara proses pengambilan keputusan dan perilaku kepemimpinan bersifat positif. Namun korelasi yang terjadi diantara dua variabel tersebut yaitu korelasi yang lemah (0.404). Hal itu terjadi karena masih adanya keraguan dalam diri mahasiswa akuntansi di STIESA dalam partisipasinya terhadap pengambilan keputusan ditingkat fakultas. Berdasarkan lampiran tabel 3, mahasiswa masih ragu dengan adanya kerjasama dengan dosen untuk meningkatkan keterampilan-keterampilan profesional $(\mathrm{M}=3.81 \mathrm{SD}=.624)$, kemudian tidak adanya keyakinan terhadap kurikulum yang dapat mengembankan visi mahasiswa $(\mathrm{M}=3.83 \mathrm{SD}=.561) \mathrm{dan}$ mahasiswa merasa tidak adanya dorongan dari dosen untuk mengembangkan nilaiOnilai perilaku mahasiswa( $\mathrm{M}=3,83$ $\mathrm{SD}=.507)$.

Mahasiswa akuntansi STIESA beranggapan bahwa perilaku kepemimpinan bersumber dari budaya organisasi $(\mathrm{M}=4.19 \mathrm{SD}=.467)$, pengetahuan $(\mathrm{M}=4.06 \mathrm{SD}=.531)$, dan moralitas $(\mathrm{M}=4.03 \mathrm{SD}=.560)$ (Lampiran tabel 5).
Tabel 2

Descriptive Statistics and Correlations Mahasiswa KUIS

\begin{tabular}{|c|c|c|c|c|c|c|c|c|}
\hline Variabel & $\begin{array}{l}\text { Me } \\
\text { an }\end{array}$ & $\begin{array}{l}\mathbf{S} \\
\mathbf{D}\end{array}$ & 1 & 2 & 3 & 4 & 5 & 6 \\
\hline $\begin{array}{l}\text { Struktur } \\
\text { Kurikulu } \\
\text { m }\end{array}$ & $\begin{array}{c}3.8 \\
6\end{array}$ & $\begin{array}{l}.6 \\
97 \\
\end{array}$ & $\begin{array}{c}1.0 \\
00\end{array}$ & $\begin{array}{c}.76 \\
0\end{array}$ & $\begin{array}{c}.89 \\
5\end{array}$ & $\begin{array}{c}.80 \\
8\end{array}$ & $\begin{array}{c}.83 \\
2\end{array}$ & $\begin{array}{c}.63 \\
0\end{array}$ \\
\hline $\begin{array}{l}\text { Citra } \\
\text { Profesi } \\
\text { Akuntansi }\end{array}$ & $\begin{array}{c}3.9 \\
6\end{array}$ & \begin{tabular}{|}
.6 \\
80
\end{tabular} & $\begin{array}{c}.76 \\
0\end{array}$ & $\begin{array}{l}1.0 \\
00\end{array}$ & $\begin{array}{c}.84 \\
1\end{array}$ & $\begin{array}{c}.78 \\
6\end{array}$ & $\begin{array}{c}.74 \\
8\end{array}$ & $\begin{array}{c}.54 \\
3\end{array}$ \\
\hline $\begin{array}{l}\text { Pengambi } \\
\text { lan } \\
\text { Keputusa } \\
n\end{array}$ & $\begin{array}{c} \\
4.0 \\
7\end{array}$ & $\begin{array}{l}.6 \\
76\end{array}$ & $\begin{array}{c}.89 \\
5\end{array}$ & $\begin{array}{c}.84 \\
1\end{array}$ & $\begin{array}{l}1.0 \\
00\end{array}$ & $\begin{array}{c}.85 \\
1\end{array}$ & $\begin{array}{c}90 \\
4\end{array}$ & $\begin{array}{c}.67 \\
2\end{array}$ \\
\hline $\begin{array}{l}\text { Nilai-nilai } \\
\text { etika }\end{array}$ & $\begin{array}{c}4.0 \\
5\end{array}$ & $\begin{array}{l}.7 \\
53 \\
\end{array}$ & $\begin{array}{c}.80 \\
8\end{array}$ & $\begin{array}{c}.78 \\
6\end{array}$ & $\begin{array}{c}.85 \\
1 \\
\end{array}$ & $\begin{array}{l}1.0 \\
00 \\
\end{array}$ & \begin{tabular}{|c|}
78 \\
1 \\
\end{tabular} & $\begin{array}{c}.65 \\
5\end{array}$ \\
\hline $\begin{array}{l}\text { Sumber } \\
\text { Kepemim } \\
\text { pinan }\end{array}$ & $\begin{array}{c}4.1 \\
5\end{array}$ & $\begin{array}{l}.7 \\
26\end{array}$ & $\begin{array}{c}.83 \\
2\end{array}$ & $\begin{array}{c}.74 \\
8\end{array}$ & .90 & $\begin{array}{c}.78 \\
1\end{array}$ & $\begin{array}{l}1.0 \\
00\end{array}$ & $\begin{array}{c}.57 \\
2\end{array}$ \\
\hline $\begin{array}{l}\text { Keteramp } \\
\text { ilan } \\
\text { Kepemim } \\
\text { pinan } \\
\end{array}$ & $\begin{array}{c}3.5 \\
8\end{array}$ & $\begin{array}{l}.5 \\
96\end{array}$ & $\begin{array}{c}.63 \\
0\end{array}$ & $\begin{array}{c}.54 \\
3\end{array}$ & $\begin{array}{c}.67 \\
2\end{array}$ & $\begin{array}{c}.65 \\
5\end{array}$ & $\begin{array}{c}.57 \\
2\end{array}$ & $\begin{array}{l}1.0 \\
00\end{array}$ \\
\hline
\end{tabular}

Sumber: Data SPSS diolah 2018

Hasil penelitian membuktikan bahwa hubungan antara struktur kurikulum dengan pilihan karir mahasiswa akuntansi KUIS bersifat positif dan berkorelasi sangat kuat (.760). Berdasarkan lampiran tabel 8 mahasiswa akuntansi KUIS merasa ragu-ragu dengan asumsi bahwa citra profesi akuntansi di mata masyarakat bukanlah hal yang nyata $(\mathrm{M}=3,18, \mathrm{SD}=$ .797). Mahasiswa akuntansi KUIS menganggap bahwa profesi akuntansi itu sangat menantang $(\mathrm{M}=4,35, \mathrm{SD}=.849)$. Gambaran profesi akuntansi dapat ditingkatkan dengan keterlibatan aktif akuntan dalam kegiatan kepemimpinan, dan sebagai hasilnya akuntan harus 
menjadi karyawan yang sangat berpengaruh dalam organisasi $(\mathrm{M}=4,35$, $\mathrm{SD}=.812)$

Sementara itu hubungan antara etika dengan pilihan karir bersifat positif dan menunjukkan adanya korelasi yang sangat kuat (.786). Berdasarkan lampiran tabel 10 mahasiswa akuntansi KUIS menganggap bahwa kurikulum dapat mengembangkan nilai etika mahasiswa (M $=3,58, \mathrm{SD}=.692)$ dan dosen selalu mendorong dan mempromosikan nilainilai etika $(\mathrm{M}=4,18, \mathrm{SD}=.797)$.

Kemudian untuk menjawab pertanyaan penelitian kedua, hasil tabel diatas menunjukan korelasi yang terjadi antara kurikulum dan perilaku kepemimpinan yaitu korelasi yang bersifat positif dengan tingkat korelasi yang kuat (.630). Sementara itu hasil pengolahan dari tabel diatas menunjukan adanya korelasi antara proses pengambilan keputusan dan perilaku kepemimpinan. korelasi yang terjadi diantara dua variabel tersebut yaitu korelasi yang bersifat positif dengan tingkat korelasi yang kuat (.672). Hal itu terjadi karena mahasiswa akuntansi di KUIS sudah merasa cukup dilibatkan dalam partisipasinya terhadap pengambilan keputusan ditingkat fakultas. Berdasarkan lampiran tabel 9, mahasiswa setuju dengan adanya kerjasama dengan dosen untuk meningkatkan keterampilan- keterampilan profesional $(\mathrm{M}=4,18, \mathrm{SD}=$ .758), kemudian adanya keyakinan terhadap kurikulum yang dapat mengembangkan visi mahasiswa $(\mathrm{M}=$ $4,09, \mathrm{SD}=.793)$ dan mereka menganggap perlu dilibatkan dalam pengembangan kurikulum $(\mathrm{M}=4,06, \mathrm{SD}=.814)$.

Selain itu hal yang mendasari terbentuknya perilaku kepemimpinan mahasiswa akuntansi KUIS bersumber dari pengetahuan $(\mathrm{M}=4,26, \mathrm{SD}=.790)$, kurikulum $(\mathrm{M}=4,15, \mathrm{SD}=.821)$, moralitas $(\mathrm{M}=4,12, \mathrm{SD}=.769)$ dan budaya oranisasi ( $\mathrm{M}=4,06, \mathrm{SD}=.814$ ) (Lampiran tabel 11).

Tabel 3

Descriptive Statistics and Correlations Mahasiswa STIESA dan KUIS

\begin{tabular}{|c|c|c|c|c|c|c|c|c|}
\hline Variabel & $\begin{array}{c}\text { Me } \\
\text { an }\end{array}$ & $\begin{array}{l}\mathbf{S} \\
\mathbf{D}\end{array}$ & 1 & 2 & 3 & 4 & 5 & 6 \\
\hline $\begin{array}{l}\text { Struktur } \\
\text { Kurikulu } \\
\text { m } \\
\end{array}$ & $\begin{array}{c}3.8 \\
2\end{array}$ & $\begin{array}{c}.5 \\
21\end{array}$ & $\begin{array}{l}1.0 \\
00\end{array}$ & $\begin{array}{c}.50 \\
9\end{array}$ & $\begin{array}{c}.77 \\
7\end{array}$ & $\begin{array}{c}.70 \\
9\end{array}$ & $\begin{array}{c}.65 \\
0\end{array}$ & $\begin{array}{c}.39 \\
5\end{array}$ \\
\hline \begin{tabular}{l|} 
Citra \\
Profesi \\
Akuntansi
\end{tabular} & $\begin{array}{c}3.9 \\
0\end{array}$ & $\begin{array}{c}.5 \\
53\end{array}$ & $\begin{array}{c}.50 \\
9\end{array}$ & $\begin{array}{l}1.0 \\
00\end{array}$ & $\begin{array}{c}.70 \\
9\end{array}$ & $\begin{array}{c}69 \\
5\end{array}$ & $\begin{array}{c}.73 \\
6\end{array}$ & $\begin{array}{c}.53 \\
6\end{array}$ \\
\hline $\begin{array}{l}\text { Pengambi } \\
\text { lan }\end{array}$ & 3.9 & .5 & .77 & .70 & 1.0 & .80 & .78 & .55 \\
\hline $\begin{array}{l}\text { Keputusa } \\
\mathrm{n}\end{array}$ & 7 & 62 & 7 & 9 & 00 & 7 & 7 & 7 \\
\hline $\begin{array}{l}\text { Nilai-nilai } \\
\text { etika }\end{array}$ & $\begin{array}{c}3.9 \\
3\end{array}$ & $\begin{array}{c}.5 \\
56\end{array}$ & \begin{tabular}{|c|}
.70 \\
9
\end{tabular} & $\begin{array}{c}.69 \\
5\end{array}$ & $\begin{array}{c}.80 \\
7 \\
\end{array}$ & $\begin{array}{l}1.0 \\
00\end{array}$ & $\begin{array}{c}.69 \\
1 \\
\end{array}$ & $\begin{array}{c}.54 \\
2\end{array}$ \\
\hline $\begin{array}{l}\text { Sumber } \\
\text { Kepemim } \\
\text { pinan }\end{array}$ & $\begin{array}{c}4.0 \\
7 \\
\end{array}$ & $\begin{array}{l}.6 \\
34\end{array}$ & $\begin{array}{c}.65 \\
0\end{array}$ & $\begin{array}{c}.73 \\
6\end{array}$ & $\begin{array}{c}.78 \\
7\end{array}$ & $\begin{array}{c}.69 \\
1\end{array}$ & $\begin{array}{l}1.0 \\
00\end{array}$ & $\begin{array}{c}.49 \\
7\end{array}$ \\
\hline $\begin{array}{l}\text { Keteramp } \\
\text { ilan } \\
\text { Kepemim } \\
\text { pinan } \\
\end{array}$ & $\begin{array}{c}3.6 \\
2\end{array}$ & $\begin{array}{c}.5 \\
76\end{array}$ & $\begin{array}{c}.39 \\
5\end{array}$ & $\begin{array}{c}.53 \\
6\end{array}$ & $\begin{array}{c}.55 \\
7\end{array}$ & $\begin{array}{c}.54 \\
2\end{array}$ & $\begin{array}{c}.49 \\
7\end{array}$ & $\begin{array}{l}1.0 \\
00\end{array}$ \\
\hline
\end{tabular}

Sumber: Data SPSS diolah 2018 
Hasil penelitian membuktikan bahwa hubungan antara struktur kurikulum dengan pilihan karir mahasiswa akuntansi di STIESA dan KUIS bersifat positif dan berkorelasi kuat (.509). Berdasarkan lampiran tabel 14 mahasiswa akuntansi STIESA dan KUIS merasa ragu-ragu dengan asumsi bahwa citra profesi akuntansi di mata masyarakat bukanlah hal yang nyata $(\mathrm{M}=3,04, \mathrm{SD}=.788)$. Mahasiswa akuntansi STIESA dan KUIS menganggap bahwa profesi akuntansi itu sangat menantang $(\mathrm{M}=4,29, \mathrm{SD}=.684)$. Gambaran profesi akuntansi dapat ditingkatkan dengan keterlibatan aktif akuntan dalam kegiatan kepemimpinan, dan sebagai hasilnya akuntan harus menjadi karyawan yang sangat berpengaruh dalam organisasi $(\mathrm{M}=4,39$, $\mathrm{SD}=$.666).

Sementara itu hubungan antara etika dengan pilihan karir bersifat positif dan menunjukkan adanya korelasi yang kuat (.695). Berdasarkan lampiran tabel 16 mahasiswa akuntansi STIESA dan KUIS menganggap bahwa dosen selalu mendorong dan mempromosikan nilainilai etika $(\mathrm{M}=4,09, \mathrm{SD}=.737)$ dan kurikulum mampu untuk mengembangkan nilai etika mahasiswa $(\mathrm{M}=3,96, \mathrm{SD}=$ $.711)$

Kemudian untuk menjawab pertanyaan penelitian kedua, hasil tabel diatas menunjukan korelasi yang terjadi antara kurikulum dan perilaku kepemimpinan yaitu korelasi yang bersifat positif dengan tingkat korelasi yang lemah (.395). Hal tersebut terjadi karena adanya keraguan mengenai pengetahuan yang dimiliki sebagai modal untuk menjadi seorang pemimpin $(\mathrm{M}=3,30, \mathrm{SD}=.749)$ dan masih timbulnya keraguan untuk menentukan dirinya sebagai seorang pemimpin atau sebagai pengikut ( $\mathrm{M}=$ $3,27, \mathrm{SD}=.833$ ) (lampiran tabel 18). Sementara itu berdasarkan hasil pengolahan dari tabel diatas menunjukan adanya korelasi antara proses pengambilan keputusan dan perilaku kepemimpinan. korelasi yang terjadi diantara dua variabel tersebut yaitu korelasi yang bersifat positif dengan tingkat korelasi yang kuat (.557). Hal itu terjadi karena mahasiswa akuntansi di STIESA dan KUIS sudah merasa cukup dilibatkan dalam partisipasinya terhadap pengambilan keputusan ditingkat fakultas. Berdasarkan lampiran tabel 15, mahasiswa menganggap perlu dilibatkan dalam pengembangan kurikulum ( $\mathrm{M}=4,04, \mathrm{SD}$ $=.711$ ), mahasiswa setuju dengan adanya kerjasama dengan dosen untuk meningkatkan keterampilan-keterampilan profesional $(\mathrm{M}=3,99, \mathrm{SD}=.712)$, dan kemudian adanya keyakinan terhadap kurikulum yang dapat mengembangkan visi mahasiswa $(\mathrm{M}=3,96, \mathrm{SD}=.690)$. 
Selain itu hal yang mendasari terbentuknya perilaku kepemimpinan mahasiswa akuntansi STIESA dan KUIS bersumber dari pengetahuan ( $\mathrm{M}=4,16$, $\mathrm{SD}=.673)$, budaya oranisasi $(\mathrm{M}=4,13$, $\mathrm{SD}=.658)$, moralitas $(\mathrm{M}=4,07, \mathrm{SD}=$ .666) dan kurikulum ( $\mathrm{M}=3,91, \mathrm{SD}=.737)$ (Lampiran tabel 17).

\section{KESIMPULAN}

Tujuan penelitian ini adalah untuk menggali pentingnya kurikulum dalam mengembangkan perilaku kepemimpinan mahasiswa akuntansi. Akuntan adalah karyawan yang memiliki kekuatan, yang bila dilakukan dapat mengaktifkan mekanisme kepemimpinan. Pengetahuan dan nilai etika merupakan atribut yang sangat penting bagi mahasiswa akuntansi sebagai pemimpin di masa depan.

Berdasarkan hasil uji korelasi di atas, dapat disimpulkan bahwa :

1. Hubungan yang terjadi antara kurikulum dan pilihan karir mahasiswa akuntansi STIESA yaitu hubungan yang bersifat negatif. Itu berarti ketika kurikulum memberikan pengetahuan lebih baik, justru pemilihan karir akan mengalami penurunan. Sementara itu ada hubungan positif dan signifikan antara etika dengan pilihan karir. Semakin baik etika yang dimiliki oleh mahasiswa akuntansi maka pemilihan karirnya juga akan semakin baik.

Sementara hubungan yang terjadi antara kurikulum dan etika terhadap pilihan karir mahasiswa KUIS menunjukan adanya hubungan yang positif dan signifikan. Artinya jika kurikulum memberikan pengetahuan yang lebih baik dan mahasiswa memiliki etika yang baik sesuai dengan standar akuntansi, maka pilihan karir mahasiswa akuntansi KUIS akan semakin baik juga.

Kemudian ketika analisis data digabung antara mahasiswa STIESA dan KUIS hasilnya menunjukkan adanya hubungan positif dan signifikan antara kurikulum dan etika terhadap pilihan karir. Korelasi yang terjadi antara kurikulum dan etika terhadap pilihan karir yaitu bersifat positif dengan tingkat korelasi yang kuat. Nilai korelasinya yaitu (.509) untuk kurikulum dan (.695) untuk etika. Artinya jika kurikulum memberikan pengetahuan yang lebih baik dan mahasiswa memiliki etika yang baik, maka pilihan karir mahasiswa akuntansi akan semakin baik juga.

2. Hubungan yang terjadi antara kurikulum dan perilaku kepemimpinan mahasiswa akuntansi 
STIESA yaitu hubungan yang bersifat negatif. Itu berarti ketika kurikulum memberikan pengetahuan lebih baik, justru perilaku kepemimpinan akan mengalami penurunan. Sementara itu ada hubungan positif dan signifikan antara proses pengambilan keputusan dengan perilaku kepemimpinan. Semakin sering terlibat dalam proses pengambilan keputusan maka perilaku kepemimpinan mahasiswa STIESA akan semakin baik.

Sementara hubungan yang terjadi antara kurikulum dan proses pengambilan keputusan terhadap perilaku kepemimpinan mahasiswa KUIS menunjukan adanya hubungan yang positif dan signifikan. Artinya jika kurikulum memberikan pengetahuan yang lebih baik dan mahasiswa semakin sering terlibat dalam proses pengambilan keputusan, maka perilaku kepemimpinan mahasiswa akuntansi KUIS akan semakin baik juga.

Kemudian ketika analisis data digabung antara mahasiswa STIESA dan KUIS hasilnya menunjukkan adanya hubungan positif dan signifikan antara kurikulum dan proses pengambilan keputusan terhadap perilaku kepemimpinan. Artinya jika kurikulum memberikan pengetahuan yang lebih baik dan mahasiswa semakin sering terlibat dalam proses pengambilan keputusan, maka perilaku kepemimpinan mahasiswa akuntansi akan semakin baik juga.

\section{REFERENCES}

Afriyenti, M., \& Misra, F. (2014). Kepemimpinan Dalam Akuntansi: Pengintegrasian Topik Dan Pengalaman Kepemimpinan $\mathrm{Ke}$ Dalam Kurikulum Akuntansi. Jurnal WRA, Vol 2, No 2, Oktober 2014

American Institute of Certified Public Accountants (AICPA). 2009. AICPA core competency framework for entry into the accounting profession. Available

at:http://www.aicpa.org/interestarea s/accountingeducation/resources/pag es/coreco petency. aspx.

Anderson, J. C., \& Gerbing, D. W. (1988). Structural equation modeling in practice: A review and recommended two step approach. Psychological Bulletin, 103(3), 411-423.

Carl S. Warren. (2015). Pengantar Akuntansi Adaptasi Indonesia. Jakarta: Salemba Empat.

Clifton, J. (2014). Small stories, positioning, and the discursive construction of leader identity in 
business meetings. Leadership, 10(1), 99-117.

Fogarty, T., \& Al-Kazemi, S. (2011).

Leadership in accounting: The new face of an old profession. Accounting \& the Public Interest, 11(1), 16-31.

Kavanagh, M. H., \& Drennan, L. (2008). What skills and attributes does an accounting graduate need? Evidence from student perceptions and employer expectations. Accounting \& Finance, 48(2), 279-300.

Laguador, J. M., \& Ramos, L. R. (2014). Industry-partners' preferences for graduates: Input on curriculum development. Journal of Education \& Literature, 1(1), 1-8.

Nunnally, J. C. (1994). Psychometric theory (3rd ed.). New York: McGraw-Hill. Permendikbud Nomor 49 Tahun 2014 tentang Standar Nasional Pendidikan Tinggi.

Saputra, Irfan Hadi. (2015). Faktor-Faktor Yang Mempengaruhi Pemilihan Karir Mahasiswa Akuntansi Untuk Menjadi Akuntan Publik Di Perguruan Tinggi Swasta Wilayah Semarang

Sari, M. (2013). Faktor-Faktor yang mempengaruhi pemilihan karir menjadi akuntan publik oleh mahasiswa departemen akuntansi fakultas ekonomi UMSU Medan. Jurnal Riset Akuntansi dan Bisnis, Vol 13 No. 2.

Schiopoiu, A. B., Mihai, M., \& Mihai, L. (2015). The leadership behaviour of the accounting students: A dilemma for higher education. International Journal of Organizational Leadership 5 299-306.

Suyantiningsih. Kepemimpinan Kurikulum (Curiculum Leadership): Perspektif baru untuk Abad 21.

Tan, L. M., \& Laswad, F. (2006). Students' beliefs, attitudes, \& intentions to major in accounting. Accounting education: An International Journal, 15(2), 167187.

Terry, George R. (1997). Prinsip-Prinsip Manajemen. Bumi Aksara: Jakarta

Wildiana, E. (2014). Faktor-faktor yang mempengaruhi pemilihan karir profesi akuntan publik bagi mahasiswa akuntansi.

Sumber dar internet

https://dianpawpaw.wordpress.com/tag/kari er-akuntan/

https://shuumalik.wordpress.com/2013/01/2 8/pengertian-etika-profesi-akuntansi/ 